\title{
Use of whole blood in the measurement of neutrophil migration
}

\author{
H AL-HADITHY, IE ADDISON, AND AH GOLDSTONE \\ From the Department of Haematology, University College Hospital, Gower Street, London WCI, UK
}

SUMMARY A whole-blood method was used for measuring neutrophil migration in micropore membranes. The method is reproducible (coefficient of variation (CV) $10.3 \%$ and $9.8 \%$ in two normal individuals tested repeatedly) and can be performed on an $0.25 \mathrm{ml}$ lithium heparin blood sample. Migration is independent of leucocyte and erythrocyte counts and is comparable with that obtained for separated cells. As in separated cell techniques, cytochalasin and casein respectively inhibit and stimulate neutrophil migration. The technique is of value when testing large numbers of samples and when only small volumes of blood can be obtained, for example, in neonates.

For the past 20 years in-vitro neutrophil migration has usually been studied by observing the movement of separated neutrophils through micropore membranes according to the Boyden technique ${ }^{1}$ and a number of modifications of this basic technique. ${ }^{2-6}$ All these methods are expensive and time-consuming ${ }^{3}{ }^{7}$ and require the use of separated leucocytes. The latter requirement means that the leucocytes are exposed to potentially unphysiological conditions and that relatively large volumes of blood are needed.

Leucocyte testing of whole blood overcomes many of the above problems, and methods for testing whole blood for T and B cells, ${ }^{8}$ responses to lectins, ${ }^{9}$ and K-cell activity ${ }^{10}$ have already been developed.

We describe a method of testing neutrophil migration in whole blood.

\section{Material and methods}

Venous blood was collected into lithium heparin ( $15 \mathrm{IU} / \mathrm{ml}$ blood) and tested as whole blood by the raft version ${ }^{6}$ of the Boyden technique ${ }^{1}$ at a usual dilution of 1 in 2 RPMI 1640. In this method, $3 \mu \mathrm{m}$ Sartorius micropore membranes are laid on filter paper soaked in medium, and whole blood $(0.25 \mathrm{ml})$ is placed in plastic caps which are inverted on to the membrane. After incubation in a moist chamber for 120 minutes the caps are removed and the membranes are washed in saline, fixed with propanol, stained with haematoxylin, and cleared with cedar wood oil. Migration through the membrane is esti-

Accepted for publication 23 June 1980 mated by measuring the leading front of neutrophils at three separate sites for each batch of cells using a $\times 16$ objective. The leading front is the part furthest from the surface of the membrane at which two or more neutrophils are still in focus together. ${ }^{3}$ The few red cells that remain after the membranes have been washed aid recognition of the surface layer. The distance (measured by the micrometer of the objective lens control) between the surface layer and the leading front provides an estimate of neutrophil migration. For every sample, the white cell and red cell counts of whole blood were measured on a Coulter $\mathrm{S}$ counter.

TEST CONDITIONS

To study the effect of plasma, neutrophil migration was measured in the presence of plasma from a normal volunteer. To do this, whole blood was centrifuged, washed, and resuspended to the original volume in control plasma.

The effect of different anticoagulants, or different dilutions of whole blood in medium, of different storage times and conditions before testing, and of different incubation times during testing was investigated.

EFFECT OF CYTOCHALASIN B AND CASEIN The effect of adding cytochalasin B to whole blood at a range of concentrations $(1 \cdot 25-40 \mu \mathrm{g} / \mathrm{ml})$ was tested. The effect of caesin $(0 \cdot 25-4 \mathrm{mg} / \mathrm{ml})$ was tested in a similar way, except that the incubation time was reduced to 60 minutes to prevent migration right through the membrane. 
COMPARISON OF WHOLE BLOOD TEST AND SEPARATED CELL TEST

As part of a larger study of host defence, ${ }^{11}$ patients with stages III and IV Hodgkin's disease were studied by different investigators in different laboratories on the same day; the same controls were used in each case. The whole-blood method was as described above. In the separated cell method, leucocytes were separated by sedimentation of red cells (in Plasmasteril; Fresenius, Bad Homburg, West Germany) and resuspended in autologous or control plasma at $2 \times 10^{9} / 1$. Thereafter they were treated as described for whole blood except that an incubation time of 30 minutes was used.

\section{Results}

EFFECT OF DIFFERENT DILUTIONS OF BLOOD AND OF DIFFERENT INCUBATION TIMES

We have found with separated cells that a concentration around $2.0 \times 10^{9}$ neutrophils/ 1 is suitable for leading front estimations. Therefore, assuming a normal range of $3-7 \times 10^{9}$ neutrophils/l, we tested blood from normal laboratory staff undiluted (1/1) and diluted 1/2 and 1/4 (in RPMI-1640 medium) for various incubation times $(30,60$, and 120 minutes). The results are shown in Figure 1. For

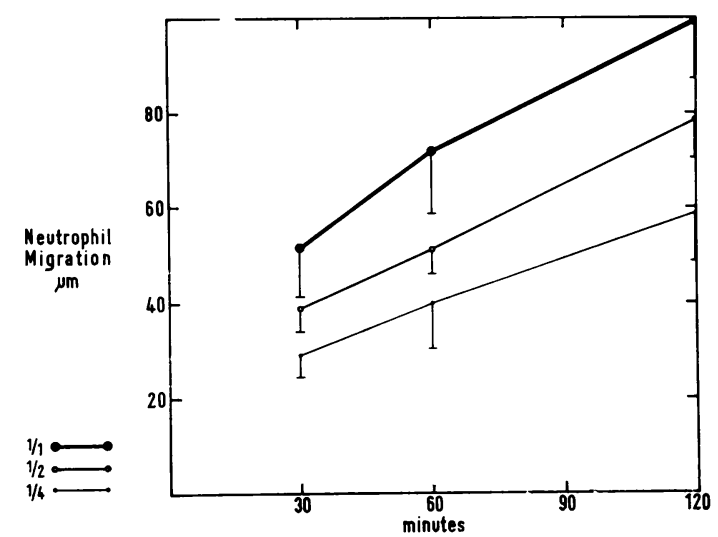

Fig. 1 Effect of different dilutions of whole blood and of different incubation times on neutrophil migration.

Error bars give the standard deviation of 36 observations.

subsequent work, a dilution of $1 / 2$ and an incubation time of 120 minutes were selected. These conditions allowed the addition of reagents to the blood under test and usually resulted in the leading front being $50 \%$ of the distance through the membrane, thereby leaving maximum opportunity for detection of decreased or increased locomotion.
The decrease in migration with dilution of blood (Fig. 1) is not due to a reduction in neutrophil numbers (see next section) but is probably due to dilution of plasma which, in our experience, is a dose-dependent stimulant of locomotion (Addison, unpublished data).

Under the standard conditions (1:2 dilution and 120 minutes' incubation) mean migration in 89 normal individuals was $78.6 \mu \mathrm{m} \pm 11.5$ (coefficient of variation (CV) $14.6 \%$ ). Two individuals were tested repeatedly (19 and 13 times, respectively) and mean values of $80.25 \mu \mathrm{m} \pm 8.25(\mathrm{CV}=10.3 \%)$ and 78.73 $\mu \mathrm{m} \pm 7 \cdot 75(\mathrm{CV}=9.8 \%)$ were obtained.

\section{EFFECT OF LEUCOCYTE AND ERYTHROCYTE}

COUNTS ON NEUTROPHIL MIGRATION

Thirty-six normals were studied, and no correlation was observed between migration and neutrophil count $(r=0.27)$ or between migration and erythrocyte count $(r=0.31)$.

\section{EFFECT OF ANTICOAGULANTS AND TIME OF STORAGE BEFORE TESTING}

The effect of anticoagulants on neutrophil migration is shown in Table 1. Similar migration was observed in the presence of lithium heparin and preservativefree heparin. The other anticoagulants were inhibitory: the effect of EDTA and citrate is presumably due to chelation of essential divalent ions, while fluoride is an inhibitor of respiration.

\section{Table 1 Effect of anticoagulants on PMN migration}

\begin{tabular}{|c|c|}
\hline & $\begin{array}{l}\text { Leading front measurements } \\
\text { on } 15 \text { normal subjects } \\
\text { (mean } \pm I S D)\end{array}$ \\
\hline $\begin{array}{l}\text { Preservative-free heparin (15 } \mathrm{IU} / \mathrm{ml}) \\
\text { Lithium heparin }(15 \mathrm{IU} / \mathrm{ml}) \\
\text { EDTA ( } 2 \mathrm{mg} / \mathrm{ml}) \\
\text { Sodium citrate }(3.8 \mathrm{mg} / \mathrm{ml}) \\
\text { Fluoride oxalate }(1 \mathrm{mg} / \mathrm{ml} \text { fluoride } \\
\qquad 3 \mathrm{mg} / \mathrm{ml} \text { oxalate })\end{array}$ & $\begin{array}{l}79 \cdot 6 \pm 10 \cdot 03 \\
80 \cdot 2 \pm 9 \cdot 9 \\
67 \cdot 2 \pm 6 \cdot 4 \\
64 \cdot 0 \pm 11 \cdot 6 \\
28 \cdot 7 \pm 9 \cdot 0\end{array}$ \\
\hline
\end{tabular}

The effect on neutrophil migration of different storage times at different temperatures is shown in Fig. 2 (15 normal individuals tested). At $4^{\circ} \mathrm{C}$ and room temperature, neutrophil migration declined slowly with storage time. On the basis of these results we keep blood for as short a time as possible before testing. However, comparisons between normal and patients' blood will probably be valid after storage over several hours (or even overnight) provided the test and normal control blood are taken simultaneously. There was a marked increase in locomotion after incubation overnight at $37^{\circ} \mathrm{C}$ (Fig. 2). The significance of this observation is not clear, but it may imply that activation of the plasma 


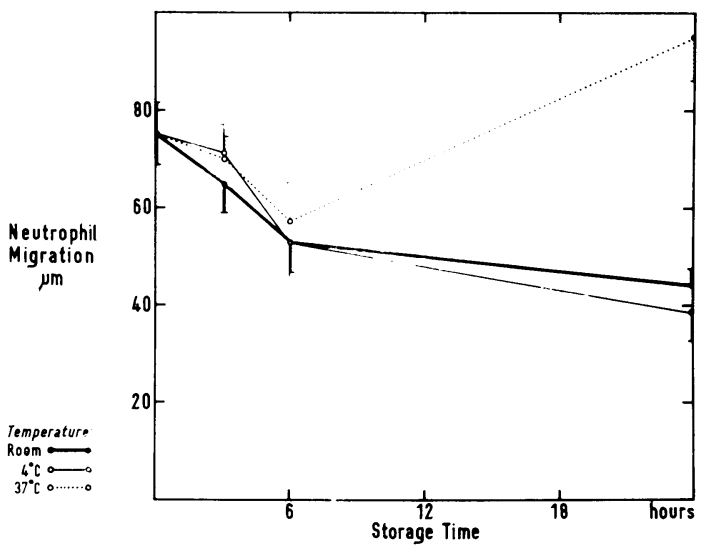

Fig. 2 Effect of storage time at different temperature on neutrophil migration. Mean of 15 individuals tested; error bars indicate the standard deviation at the different times and temperatures of testing.

can take place during incubation, or that there is a loss of an inhibitor from the plasma or cell surface.

\section{COMPARISON OF WHOLE-BLOOD TEST AND SEPARATED CELL TEST}

The results of testing autologous plasma are shown in Fig. 3, and it is clear that, when expressed as a ratio of the control, very similar results were obtained for separated and unseparated neutrophils $(r=0.44)$. Furthermore, this good correlation $(\mathrm{P}<0.001)$ was observed despite the fact that many of the patients were anaemic and had a high ESR and an abnormal white cell count. Since the separated cell test is done at a constant white cell count $(2 \times$ $\left.10^{9} / 1\right)$, this result indicates that different neutrophil counts do not invalidate the whole-blood technique.

Similar results were obtained in the presence of heterologous plasma, a highly significant correlation $(\mathrm{P}=0.0001, \mathrm{r}=0.57)$ again being observed between whole-blood and separated leucocyte tests.

EFFECT OF CYTOCHALASIN B AND CASEIN The results are shown in Fig. 4 and Table 2. As is seen from Fig. 4, cytochalasin B produced a dose-

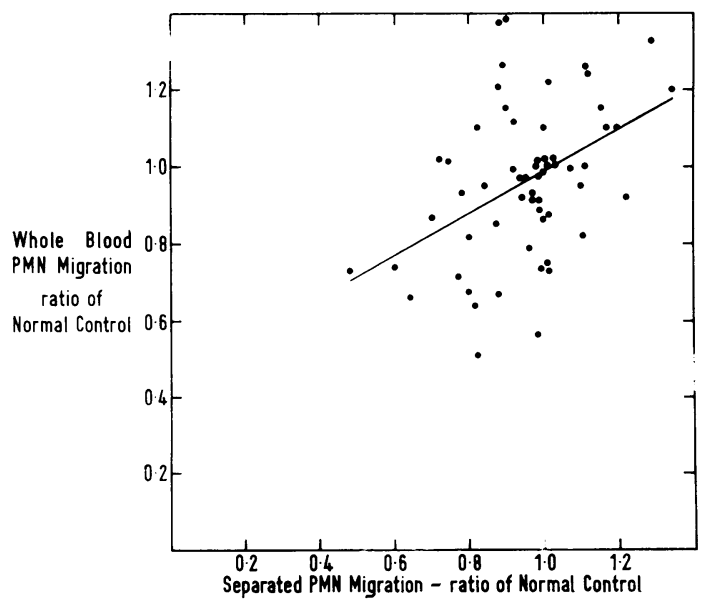

Fig. 3 Comparison of separated and whole-blood neutrophil (PMN) migration in autologous plasma. Results expressed as a ratio of the normal control of the day.

related inhibition of migration, which resembled that observed when separated cells are tested in the presence of cytochalasin B. ${ }^{12}$ At a high concentration of cytochalasin B $(>20 \mu \mathrm{g} / \mathrm{ml})$ no neutrophil entered the micropore membrane, and, after washing and staining, very few were seen at the starting surface.

The effect of adding different concentrations of casein is shown in Table 2. Concentrations of 0.25 and $0.5 \mathrm{mg} / \mathrm{ml}$ had no effect; $1 \mathrm{mg} / \mathrm{ml}$ had a chemotactic effect in a minority of cases, while $4 \mathrm{mg} / \mathrm{ml}$ was inhibitory; $2 \mathrm{mg} / \mathrm{ml}$ had a predictable stimulatory effect, but it should be noted from the wide standard deviation that individual samples responded to different extents.

\section{Discussion}

We have shown that neutrophils move from un separated blood into a micropore membrane in sufficient numbers to allow accurate measurement of neutrophil migration. This observation formed the

Table 2 Neutrophil migration in the presence $(+)$ or absence $(-)$ of various concentrations of casein

\begin{tabular}{|c|c|c|c|c|c|c|c|c|c|}
\hline & \multicolumn{2}{|c|}{$0.25 \mathrm{mg} / \mathrm{ml}$} & \multicolumn{2}{|l|}{$0.5 \mathrm{mg} / \mathrm{ml}$} & \multicolumn{2}{|l|}{$1.0 \mathrm{mg} / \mathrm{ml}$} & \multicolumn{2}{|l|}{$2.0 \mathrm{mg} / \mathrm{ml}$} & \multirow[t]{2}{*}{$4 \mathrm{mg} / \mathrm{ml}$} \\
\hline & + & - & 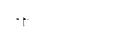 & - & + & - & + & - & \\
\hline Mean $t$ ISD & $50 \cdot 8 \pm 9$ & $46 \cdot 7: 7 \cdot 3$ & $55 \cdot 9-8 \cdot 8$ & $51 \cdot 4+9 \cdot 8$ & $61 \cdot 7 \pm 11 \cdot 7$ & $52 \cdot 9 \pm 10 \cdot 6$ & $82 \cdot 4 \pm 18 \cdot 9$ & $53 \cdot 7+8 \cdot 9$ & $\begin{array}{l}\text { Cell damage } \\
\text { occurs and few } \\
\text { cells are seen in } \\
\text { membrane }\end{array}$ \\
\hline $\begin{array}{l}\text { No. of } \\
\text { samples }\end{array}$ & \multicolumn{2}{|c|}{13} & \multicolumn{2}{|c|}{23} & \multicolumn{2}{|c|}{20} & \multicolumn{2}{|c|}{34} & 7 \\
\hline $\begin{array}{l}\text { P values for } \\
\text { paired } t \text { test }\end{array}$ & \multicolumn{2}{|c|}{$P>0 \cdot 2$} & \multicolumn{2}{|c|}{$P>0.1$} & \multicolumn{2}{|c|}{$0.01<P<0.05$} & \multicolumn{2}{|c|}{$P \ll 0.001$} & \\
\hline
\end{tabular}




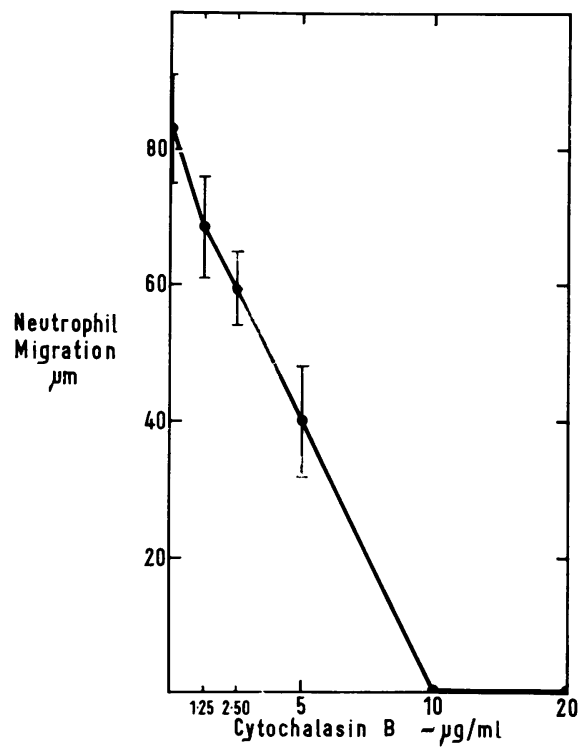

Fig. 4 Effect of cytochalasin B on neutrophil migration. Error bars give the standard deviation (15 tests at each concentration of cytochalasin).

basis of a simple, rapid, and reproducible wholeblood test of neutrophil migration. The use of whole blood rather than separated leucocytes results in a considerable saving of time and means that only a small volume of blood (even with duplicates, a total volume of $0.25 \mathrm{ml}$ ) is required. Furthermore, testing of unseparated leucocytes avoids any selection of cells or changes in cell physiology and retains interactions between blood components.

The use of the whole-blood technique means that testing cannot be carried out at a constant neutrophil count. However, we have shown that variations of both leucocyte and erythrocyte counts within the normal range had no effect on neutrophil migration. Furthermore, comparison of the whole-blood and separated cell techniques in Hodgkin's disease patients (many of whom were leucopenic and anaemic) showed that anaemia and leucopenia did not invalidate the results obtained by the wholeblood method.

Our studies of different anticoagulants and lengthening storage times showed that lithium heparin and preservative-free heparin samples yielded similar results. This indicates that routine blood chemistry samples in lithium heparin bottles are suitable for the test. Storage of blood for considerable periods before testing did not invalidate the results. A gradual reduction of migration with time was observed, and, therefore, if the sample is not being tested immediately, the control of the specimens should be taken at the same time. The inhibition and stimulation observed with cytochalasin and casein respectively resembled that seen with separated neutrophils; these results further validate the whole-blood technique.

The availability of a reliable and rapid wholeblood technique means that neutrophil migration can now be measured in large series of patients and in situations (eg, premature neonates) where only a small volume of blood can be obtained. Furthermore, whole-blood methods can also be used to study phagocytosis and killing of microorganisms ${ }^{13}$ and so provide a panel of neutrophil function tests on a given patient.

We thank Dr JC Cawley for his help and advice. Mary Gandossini performed the tests on separated neutrophils and has kindly allowed us to incorporate her data. We also thank Miss P Richardson and Mrs C Sanchez for typing the manuscript.

\section{References}

${ }^{1}$ Boyden SV. The chemotactic effect of mixtures of antibody and antigen on polymorphonuclear leucocytes. $J$ Exp Med 1962;115:453-66.

2 Baum J, Mowat AG, Kirk JA. A simplified method for the measurement of chemotaxis of polymorphonuclear leucocytes from human blood. J Lab Clin Med 1971; 77:501-9.

${ }^{3}$ Zigmond SH, Hirsch JG. Leucocyte locomotion and chemotaxis. New methods for evaluation and demonstration of a cell-derived chemotactic factor. $J$ Exp Med 1973; $137: 387-410$.

${ }^{4}$ Gallin JI, Clark RA, Kimball HR. Granulocyte chemotaxis: an improved invitro assay employing ${ }^{51} \mathrm{Cr}$-labelled granulocyte. J Immunol 1973;110:233-40.

5 Cutler JE. A simple invitro method for studies on chemotaxis. Proc Soc Exp Biol Med 1974;147:471-4.

- Addison IE, Babbage JW. A raft technique for chemotaxis: a versatile method suitable for clinical studies. $J$ Immunol Methods 1976;10:385-8.

${ }^{7}$ Keller HU. Studies on chemotaxis III. Modification of Boyden's technique for the evaluation of chemotactic agents. Immunology 1966;10:225-30.

${ }^{8}$ Pepys M, Santegna-Guidetti C, Mirah DD, WansboroughJones MH, Dash AC. Enumeration of immunoglobulin bearing lymphocytes in whole peripheral blood. Clin Exp Immunol 1976;26:91-4.

- Luquetti A, Janossy G. Lymphocytes activation. VIII. The application of a whole blood test to the quantitative analysis of PHA responsive T cells. J Immunol Methods 1976;10:7-25.

${ }^{10}$ Gale D, MacLennan ICM. A method of measuring antibody and phyto haemagglutinin-induced lymphocytedependent cytotoxicity using whole blood. Clin Exp Immunol 1976;23:252-7.

11 Addison IE, Babbage JW, Gandossini M, Souham i RL. Assessment of host defence against infection during chemotherapy of Hodgkin's Disease. Cancer Chemother Pharmacol 1978;1:129-33. 
12 Zigmond SH, Hirsch JG. Effects of cytochalasin B on polymorphonuclear leucocyte locomotion, phagocytosis and glycolysis. Exp. Cell Res 1972;73:383-93.

${ }^{13}$ Al-Hadithy H, Addison IE, Goldstone AH. A rapid wholeblood technique for assessment of neutrophil phagocy- tosis and killing. Clin Lab Haemat in press.

Requests for reprints to: Dr AH Goldstone, Department of Haematology, University College Hospital, Gower Street, London WC1E 6AU. 